\title{
Thyroid function in girls with central precocious puberty
}

\author{
Geehae Jung, MD', \\ Seok-Bin Oh, MD', \\ Won Young Lee, MD', \\ Hye Ryun Kim, MD, PhD', \\ Hyo-Kyoung Nam, MD, PhD', \\ Jae Hyun Kim, MD, PhD', \\ Young-Jun Rhie, MD, PhD', \\ Kee-Hyoung Lee, MD, PhD ${ }^{1}$ \\ 'Department of Pediatrics, Korea \\ University College of Medicine, Seoul, \\ Korea \\ ${ }^{2}$ Department of Pediatrics, Seoul \\ National University College of Medi- \\ cine, Seoul, Korea
}

Purpose: Obesity is a well-known risk factor for central precocious puberty (CPP). Recently, elevated thyroid stimulating hormone (TSH) was reported in obese youth. However, few data regarding the relationship between CPP and TSH are available. The aim of this study was to evaluate thyroid function in girls with CPP and the relationship between CPP and serum TSH concentration.

Methods: This was a retrospective cross-sectional study. A total of 1,247 girls aged between 6.0 and 8.9 years who had undergone a gonadotropin-releasing hormone $(\mathrm{GnRH})$ stimulation test to determine the presence of puberty were studied. Subjects were classified into CPP $(n=554)$ and non-CPP $(n=693)$ groups according to the results of the $\mathrm{GnRH}$ stimulation test. Characteristics and laboratory data of the CPP and non-CPP groups were compared and correlations between those characteristics and laboratory data and TSH concentration were evaluated. Serum TSH concentration in the CPP group was higher than that of the non-CPP group (3.19 $\pm 1.55 \mathrm{mIU} / \mathrm{L}$ vs. $2.58 \pm 1.34 \mathrm{mIU} / \mathrm{L}, P<0.001)$.

Results: Serum free thyroxine (fT4) concentration in the CPP group was notably lower than that of the non-CPP group $(1.38 \pm 0.14 \mathrm{ng} / \mathrm{dL}$ vs. $1.44 \pm 0.18 \mathrm{ng} / \mathrm{dL}$, $P<0.001)$. Across all subjects, 149 girls (11.9\%) had hyperthyrotropinemia. The prevalence of hyperthyrotropinemia was higher in the CPP group compared to the non-CPP group (15.7\% vs. 8.9\%, $P<0.001)$. TSH concentrations were positively correlated with age, height, weight, BMI, bone age, bone age advance, insulin-like growth factor 1 (IGF-1), IGF-1 standard deviation score, basal luteinizing hormone (LH), peak LH and basal follicle-stimulation hormone. TSH concentrations were negatively correlated with fT4. Multiple linear regression analysis showed that age $(\beta=0.548, P<0.001)$ and peak $\mathrm{LH}(\beta=0.019, P=0.008)$ were independently associated with serum TSH concentration.

Conclusion: Hyperthyrotropinemia in girls with CPP tends to be associated with pubertal LH elevation. In conclusion, pubertal onset may be associated with thyroid function.

\section{Keywords: Precocious puberty, Thyroid hormone, Obesity}

\section{Introduction}

Address for correspondence:

Young-Jun Rhie, MD, PhD

Department of Pediatrics, Korea University Ansan Hospital, Korea University College of Medicine, 123 Jeokgem-ro Danwon-gu, Ansan 15355, Korea

Tel: +82-31-412-4846

Fax: +82-31-405-8951

E-mail: human21@korea.ac.kr

https://orcid.org/0000-0002-12506469
Puberty is a period of physical and behavioral changes. ${ }^{1)}$ In this period, reproductive systems
are maturated by hypothalamic-pituitary-gonadal axis activation. The onset of puberty is
affected by many hormones and genes and even the environment. ${ }^{2)}$ In healthy condition,
genetic features tend to determine pubertal changes. Leptin and ghrelin are hormones that are
supposed to affect to the beginning of puberty. ${ }^{1,2)}$ Leptin, a hormone produced by adipocyte,
is mainly thought to influence the pubertal onset. It has been found to have direct stimulatory
effects on the secretion of gonadotropin-releasing hormone (GnRH) and gonadotropin.
"Precocious puberty" is defined as the development of pubertal changes before the age of 8 
in girls and 9 in boys and increasing numbers of children are being diagnosed with precocious puberty as childhood obesity is also increasing. ${ }^{4)}$ There have been many investigations about the factors that promote these early changes such as races, maternal menarche, child's body weight, and body mass index (BMI) including environmental influences. ${ }^{5,6)}$ There are clear associations between childhood obesity and early pubertal changes. ${ }^{3)}$ Although the cause of this relationship is still not fully understood, as excessive leptin level precedes the pubertal LH elevation and the timing of menarche is related to serum leptin level, it is thought that leptin plays a key role in pubertal onset. ${ }^{3,7}$

Obesity is a metabolic disease that affects the endocrinological system and a range of researches about the relationship between obesity and hormones has been conducted. In particular, there is much research about the relationship between obesity and thyroid function since thyroid hormones modulate metabolic pathways which is relevant to basal metabolic rate. ${ }^{8)}$ Most papers have reached the conclusion that thyroid function is usually normal in obese patients, ${ }^{9)}$ although thyroid stimulation hormone (TSH) and BMI are positively correlated. ${ }^{10)}$ The causal relationship between TSH and BMI is still unclear, however TSH levels are usually elevated and free thyroxine (fT4) levels are in the normal range in obese people. ${ }^{9,11)}$

Central precocious puberty (CPP) is strongly affected by obesity and so it is reasonable to consider the relationship between CPP and thyroid function. However, few data regarding the relationship between $\mathrm{CPP}$ and thyroid function are available. Therefore, the aim of this study was to evaluate thyroid function in girls with CPP and the relationship between CPP and serum TSH concentration.

\section{Materials and methods}

\section{Study population}

This was a retrospective cross-sectional study. Subjects were girls who had visited the Pediatric Endocrinology Clinic at Korea University Ansan Hospital between March 2013 and February 2017 for precocious puberty evaluation. Subjects showed signs of the pubertal development such as breast development, pubic hair or relatively tall height comparing to peers. A total of 1,247 girls aged between 6.0 and 8.9 years who had undergone a GnRH stimulation test to determine the onset of puberty were included in this study. All the subjects showed Tanner breast scores $\geq$ II before the age of 8 years old. All subjects showed neither clinical hypothyroidism, hyperthyroidism nor CPP caused by organic reasons.

\section{Clinical data collection}

Patient data was collected from medical records through a retrospective review. Measurement of height and weight had been performed in all subjects. Height was measured to the nearest $0.1 \mathrm{~cm}$ using a rigid stadiometer. Weight was measured to the nearest $0.1 \mathrm{~kg}$ using a calibrated balance scale. Height standard deviation score (SDS), weight SDS and BMI SDS were calculated by using the Cole's Lambda Mu Sigma method according to 2007 Korean National Growth Chart. Bone age had been measured by a single pediatric endocrinologist using the Greulich and Pyle method.

To diagnose CPP, a GnRH stimulation test had been performed. Basal serum samples were obtained prior to $\mathrm{GnRH}$ injection. The GnRH $(0.1 \mathrm{mg})$ was administered intravenously for 1 minute, and poststimulation samples were taken at 30,45 , 60 , and 90 minutes to measure the luteinizing hormone (LH) and follicle-stimulation hormone (FSH) levels. Serum LH and FSH levels were measured using electrochemiluminescence technology (Cobas 6000, Roche Diagnostics, Indianapolis, IN, USA).

Serum concentration data for insulin-like growth factor-1 (IGF-1), insulin-like growth factor binding protein-3 (IGFBP-3), thyroid stimulating hormone (TSH) and fT4 had been also collected. IGF-1 SDS and IGFBP-3 SDS was calculated based on the study by Hyun et al. ${ }^{12)}$ Serum IGF-1, serum TSH and fT4 levels were measured using radioimmunoassay methods (Gamma Pro, Seyeong NDS Co., Seoul, Korea). Serum IGFBP-3 was measured using radioimmunoassay methods (Cobra II 5010, Packard BioScience Co., Midland, ON, Canada ).

\section{Definition}

CPP was diagnosed when LH levels during the GnRH stimulation test peaked at above $5 \mathrm{IU} / \mathrm{L}$ and bone age was advanced more than 1 year compared to chronological age. ${ }^{1)}$ Subjects were classified into CPP ( $\mathrm{n}=554)$ and non-CPP $(\mathrm{n}=693)$ groups according to the results of GnRH stimulation test. Hyperthyrotropinemia was defined as elevated TSH $(\mathrm{TSH} \geq 5.0$ $\mathrm{mIU} / \mathrm{L})$ in serum concentration and normal fT4 level $(0.8 \mathrm{ng} /$ $\mathrm{dL}<\mathrm{fT} 4<1.9 \mathrm{ng} / \mathrm{dL}$ ) based on the study by Cho et al. ${ }^{13)}$

\section{Statistical analyses}

IBM SPSS Statistics ver. 20.0 (IBM Co., Armonk, NY, USA) was used for the statistical analyses. Data are expressed as mean \pm standard deviation. An independent $t$-test was used to compare the CPP and non-CPP groups and Pearson's correlation test was used to analyze the relationship among multiple characteristics and TSH concentration; $P$-values under $<0.05$ were considered statistically significant. To compare the prevalence of hyperthyrotropinemia between the CPP and non-CPP groups, an chi-square test was conducted. Moreover, a multiple linear regression analysis test was used to investigate the independent factors influencing TSH levels by controlling confounding factors in CPP group.

\section{Results}

Comparing characteristics between the CPP and non-CPP 
groups, there were significant differences in serum TSH and serum fT4 levels. TSH concentration in the CPP group was significantly higher than that of the non-CPP group $(3.19 \pm 1.55$ $\mathrm{IU} / \mathrm{L}$ vs. $2.58 \pm 1.34 \mathrm{IU} / \mathrm{L}, P<0.001)$. Serum $\mathrm{fT} 4$ concentration in the CPP group was significantly lower than that of the nonCPP group $(1.38 \pm 0.14 \mathrm{ng} / \mathrm{dL}$ vs. $1.44 \pm 0.18 \mathrm{ng} / \mathrm{dL}, P<0.001)$. Most importantly, the proportion of hyperthyrotropinemia was notably higher in the CPP group than in the non-CPP group $(15.7 \%$ vs. $8.9 \%, P<0.001)$.

Bone age, bone age advances, IGF-1, IGF-1 SDS, LH and basal and peak FSH were also significantly higher in the CPP than in the non-CPP group. Weight, weight- SDS, BMI and BMI SDS were higher in the non-CPP than the CPP group.

However, age, height, height SDS, IGFBP-3 and IGFBD-3 SDS showed no differences between the 2 groups. (Table 1)

We analyzed the correlation of these characteristics with TSH concentration. TSH concentration had a positive correlation with age, height, weight, BMI, bone age, IGF-1, IGF-1 SDS, basal LH, peak LH and basal FSH. Additionally, TSH concentration showed a negative correlation with fT4. Contrastingly, height SDS, weight SDS, BMI SDS, IGFBP-3, IGFBP-3 SDS and peak FSH showed no correlation with TSH level (Table 2).

To investigate the independent predictor factor of serum TSH level, a multiple linear regression test was used. Age, height, weight, BMI, IGF-1, basal LH, peak LH, basal FSH, and

Table 1. Comparison of characteristic and laboratory data between CPP and non-CPP groups

\begin{tabular}{|c|c|c|c|}
\hline Variable & CPP $(n=554)$ & Non-CPP $(n=693)$ & $P$-value \\
\hline Age (yr) & $8.11 \pm 0.49$ & $8.12 \pm 0.57$ & 0.828 \\
\hline Height (cm) & $129.7 \pm 5.7$ & $129.6 \pm 5.8$ & 0.853 \\
\hline Height SDS & $0.69 \pm 0.87$ & $0.68 \pm 0.91$ & 0.821 \\
\hline Weight (kg) & $29.8 \pm 5.6$ & $30.7 \pm 6.2$ & 0.009 \\
\hline Weight SDS & $0.64 \pm 0.87$ & $0.76 \pm 0.93$ & 0.018 \\
\hline $\mathrm{BMI}\left(\mathrm{kg} / \mathrm{m}^{2}\right)$ & $17.6 \pm 2.4$ & $18.1 \pm 2.7$ & $<0.001$ \\
\hline BMI SDS & $0.43 \pm 0.96$ & $0.62 \pm 1.02$ & 0.001 \\
\hline Bone age (yr) & $10.28 \pm 0.54$ & $9.07 \pm 0.77$ & $<0.001$ \\
\hline Bone age advance (yr) & $2.17 \pm 0.54$ & $0.95 \pm 0.68$ & $<0.001$ \\
\hline IGF1 (ng/mL) & $303.02 \pm 104.17$ & $258.01 \pm 85.35$ & $<0.001$ \\
\hline IGF1 SDS & $0.78 \pm 1.19$ & $0.26 \pm 1.00$ & $<0.001$ \\
\hline IGFBP3 (ng/mL) & $2,881.79 \pm 607.93$ & $2,855.63 \pm 588.56$ & 0.457 \\
\hline IGFBP3 SDS & $-0.01 \pm 1.14$ & $-0.06 \pm 1.13$ & 0.430 \\
\hline Basal LH (IU/L) & $0.29 \pm 0.59$ & $0.10 \pm 0.06$ & $<0.001$ \\
\hline Peak LH (IU/L) & $11.46 \pm 9.07$ & $3.20 \pm 1.43$ & $<0.001$ \\
\hline Basal FSH (IU/L) & $2.42 \pm 1.46$ & $1.58 \pm 0.85$ & $<0.001$ \\
\hline Peak FSH (IU/L) & $13.94 \pm 4.67$ & $12.09 \pm 3.70$ & $<0.001$ \\
\hline TSH (mIU/L) & $3.19 \pm 1.55$ & $2.58 \pm 1.34$ & $<0.001$ \\
\hline Free T4 (ng/dL) & $1.38 \pm 0.14$ & $1.44 \pm 0.18$ & $<0.001$ \\
\hline Hyperthyrotropinemia & $87(15.7)$ & $62(8.9)$ & $<0.001$ \\
\hline
\end{tabular}

Values are presented as mean \pm standard deviation or number (\%). CPP, central precocious puberty; SDS, standard deviation score; BMI, body mass index; IGF-1, insulin-like growth factor 1; IGFBP 3, insulin-like growth factor-binding protein 3; LH, luteinizing hormone; FSH, follicle stimulating hormone; Free T4, free thyroxine; $\mathrm{TSH}$, thyroid stimulating hormone. peak FSH were analyzed. Age $(\beta=0.548, P<0.001)$ and peak LH $(\beta=0.019 ; P=0.008)$ were proven as independent factors to influence serum TSH concentration (Table 3).

\section{Discussion}

To the best of our knowledge, this study is the first research to investigate the relationship between TSH levels and CPP.

In this study, the prevalence of hyperthyrotropinemia was higher in the CPP group compared to the non-CPP group. Most importantly, age and peak LH were proven as independent predictor factors of serum TSH concentration. This means that pubertal onset may be associated with thyroid function.

Table 2. Correlation of characteristic and laboratory data with TSH concentration

\begin{tabular}{lcr}
\hline Variable & $r$ & $p$-value \\
\hline Age & 0.216 & $<0.001$ \\
Height & 0.130 & $<0.001$ \\
Height SDS & 0.009 & 0.758 \\
Weight & 0.122 & $<0.001$ \\
Weight SDS & 0.041 & 0.153 \\
BMI & 0.082 & 0.004 \\
BMI SDS & 0.049 & 0.085 \\
Bone age & 0.245 & $<0.001$ \\
Bone age advance & 0.121 & $<0.001$ \\
IGF1 & 0.104 & $<0.001$ \\
IGF1 SDS & 0.083 & 0.003 \\
IGFBP3 & 0.051 & 0.083 \\
IGFBP3 SDS & 0.024 & 0.418 \\
Basal LH & 0.086 & 0.002 \\
Peak LH & 0.138 & $<0.001$ \\
Basal FSH & 0.115 & $<0.001$ \\
Peak FSH & 0.030 & 0.285 \\
Free T4 & -0.133 & $<0.001$ \\
\hline
\end{tabular}

TSH, thyroid stimulating hormone; SDS, standard deviation score; BMI, body mass index; IGF-1, insulin-like growth factor 1; IGFBP 3, insulinlike growth factor-binding protein 3; LH, luteinizing hormone; FSH, follicle stimulating hormone; Free T4, free thyroxine; $r$, coefficient of correlation.

Table 3. Results of multiple linear regression analysis of factors associated with TSH concentration

\begin{tabular}{lccc}
\hline Variable & Unstandardized coefficient $\beta$ & S.E. & P-value \\
\hline Age & 0.548 & 0.078 & $<0.001$ \\
BMI & 0.042 & 0.016 & 0.125 \\
IGF1 & 0.001 & 0.000 & 0.129 \\
Basal LH & -0.090 & 0.129 & 0.484 \\
Peak LH & 0.019 & 0.007 & 0.008 \\
Basal FSH & 0.065 & 0.041 & 0.110 \\
Peak FSH & 0.014 & 0.011 & 0.208
\end{tabular}

$\mathrm{TSH}$, thyroid stimulating hormone; BMI, body mass index; IGF-1, insulin-like growth factor 1; LH, luteinizing hormone; FSH, follicle stimulating hormone; S.E., standard error (the standard deviation of its sampling distribution). 
Puberty occurs when there is reactivation of the hypothalamic-pituitary-gonadal axis. ${ }^{2}$ Several factors are considered to influence the onset of puberty such as race, maternal menarche, low birth weight, excessive weight gain or obesity and, even environmental factors. ${ }^{14)}$ There have been many investigations into obesity's effect on the onset of puberty but the exact mechanism is still unknown. ${ }^{15)}$ Some studies suggest that leptin appears to be a main promoting factor in pubertal development. As leptin increases proportionally according to the amount of adipocyte, obese children have high levels of leptin. Leptin seems to accelerate GnRH pulse frequency. ${ }^{3,4)}$

Obesity also influences thyroid hormone levels. ${ }^{16)}$ Although thyroid function is usually normal in obese subjects, it is known that TSH and BMI are positively correlated. ${ }^{11,17)}$ Several studies have revealed that TSH, T3 is higher in obese children than in control groups and, contrastingly, that $\mathrm{T} 4$ has no significant difference between the 2 groups in the absence of thyroid antibodies. ${ }^{18-20)}$ The causes of thyroid hormonal changes in obese patient are various; autoimmunity, mutation of the TSH receptor gene, leptin, thyroid hormone resistance, mitochondrial dysfunction, and an adaptation process to increase energy expenditure are considered to influence thyroid function. ${ }^{9)}$ So far, there are many conflicting views as whether elevated TSH induces obesity or obesity itself induces TSH elevation., ${ }^{9,11,16)}$ Winter et al. ${ }^{21)}$ proved that derangement in the hypothalamicpituitary axis is a cause of increased TSH levels in obesity. Conversely, Reinehr et al. ${ }^{22)}$ suggest that increased TSH levels in obesity are an adaptation mechanism to increased resting energy expenditure.

Considering the relationship between CPP, obesity, and TSH levels, it may be thought that because obese patients tend to have CPP, a CPP group may have high levels of TSH. It is easily thought that a tendency to obesity in a CPP group is relevant to TSH elevation. However, in this study, the CPP group had lower average of BMI SDS than the non-CPP group. This result is different to most of the related researches. ${ }^{4)}$ This difference may be related to the subject's characteristics. As the subjects in this study were girls who were suspected of precocious puberty as showing clinical symptoms of puberty such as breast budding.

In this study, age, height, weight, bone age, IGF-1, basal LH, peak LH, basal FSH and also BMI had positive relationships with TSH. However, only age and peak LH showed as independent factors in the multiple regression test, hence the older the patient and the higher the peak LH level, the higher the TSH level that was found. Therefore, it is not obesity but puberty that is related with an elevation in TSH.

This may be explained by the molecular similarity of these hormones. FSH, LH, human chorionic gonadotropin and TSH are glycoprotein hormones which are similarly composed with a common a subunit and specific $\beta$ subunits. ${ }^{23)}$ Thyrotropin releasing hormone (TRH) and GnRH have several common proteins that involve the regulation of TRH and $\mathrm{GnRH}$ receptors. This interaction may induce high levels of both LH and $\mathrm{TSH}^{24,25)}$

There are limitations to this study. Firstly, no sex and age- matched healthy control group was included; only data from girls who were suspected of CPP were compared. In addition, the thyroid function test was only conducted once when the subjects first underwent the GnRH stimulation test. No followup data was taken. There is also a lack of data about thyroid hormone antibodies.

In conclusion, we suggest that hyperthyrotropinemia is relevant to pubertal onset. Elevated TSH in girls with CPP should be associated with pubertal LH elevation. Still, no association has been found between elevated TSH in CPP and obesity. Further longitudinal studies with normal control groups are needed to investigate the causal relationship between CPP and hyperthyrotropinemia.

\section{Ethical statement}

This was a retrospective study, and it was approved by the Institutional Review Board (IRB) at Korea University Ansan Hospital in Ansan, South Korea (approval number: 2018AS0080). Informed consent was waived by the IRB.

\section{Conflict of interest}

No potential conflict of interest relevant to this article was reported.

\section{Acknowledgments}

An earlier version of this study has been presented at Endoannual-meetings according to the following link: https://www. endocrine.org/meetings/endo-annual-meetings/abstractdetails?ID=6094.

\section{References}

1. Carel JC, Léger J. Clinical practice. Precocious puberty. N Engl J Med 2008;358:2366-77.

2. Roa J, García-Galiano D, Castellano JM, Gaytan F, Pinilla L, Tena-Sempere M. Metabolic control of puberty onset: new players, new mechanisms. Mol Cell Endocrinol 2010;324:87-94.

3. Burt Solorzano CM, McCartney CR. Obesity and the pubertal transition in girls and boys. Reproduction 2010; 140:399-410.

4. Kaplowitz PB. Link between body fat and the timing of puberty. Pediatrics 2008;121 Suppl 3:S208-17.

5. Berberoğlu M. Precocious puberty and normal variant puberty: definition, etiology, diagnosis and current management. J Clin Res Pediatr Endocrinol 2009;1:164-74.

6. Buck Louis GM, Gray LE Jr, Marcus M, Ojeda SR, Pescovitz $\mathrm{OH}$, Witchel SF, et al. Environmental factors and puberty timing: expert panel research needs. Pediatrics 2008;121 Suppl 3:S192-207. 
7. Palmert MR, Radovick S, Boepple PA. Leptin levels in children with central precocious puberty. J Clin Endocrinol Metab 1998;83:2260-5.

8. Roti E, Minelli R, Salvi M. Thyroid hormone metabolism in obesity. Int J Obes Relat Metab Disord 2000;24 Suppl 2:S113-5.

9. Pacifico L, Anania C, Ferraro F, Andreoli GM, Chiesa C. Thyroid function in childhood obesity and metabolic comorbidity. Clin Chim Acta 2012;413:396-405.

10. Biondi B. Thyroid and obesity: an intriguing relationship. Oxford: Oxford University Press, 2010.

11. Reinehr T. Obesity and thyroid function. Mol Cell Endocrinol 2010;316:165-71.

12. Hyun SE, Lee BC, Suh BK, Chung SC, Ko CW, Kim HS, et al. Reference values for serum levels of insulin-like growth factor-I and insulin-like growth factor binding protein-3 in Korean children and adolescents. Clin Biochem 2012;45:16-21.

13. Cho WK, Nam HK, Kim JH, Rhie YJ, Chung S, Lee KH, et al. Thyroid Function in Korean Adolescents with Obesity: Results from the Korea National Health and Nutrition Examination Survey VI (2013-2015). Int J Endocrinol 2018;2018:6874395.

14. Parent AS, Teilmann G, Juul A, Skakkebaek NE, Toppari J, Bourguignon JP. The timing of normal puberty and the age limits of sexual precocity: variations around the world, secular trends, and changes after migration. Endocr Rev 2003;24:668-93.

15. Biro FM, Khoury P, Morrison JA. Influence of obesity on timing of puberty. Int J Androl 2006;29:272-7.

16. Bastemir M, Akin F, Alkis E, Kaptanoglu B. Obesity is associated with increased serum TSH level, independent of thyroid function. Swiss Med Wkly 2007;137:431-4.

17. Marwaha RK, Tandon N, Desai AK, Kanwar R, Sastry A, Narang A, et al. The evolution of thyroid function with puberty. Clin Endocrinol (Oxf) 2012;76:899-904.

18. Reinehr T, de Sousa G, Andler W. Hyperthyrotropinemia in obese children is reversible after weight loss and is not related to lipids. J Clin Endocrinol Metab 2006;91:3088-91.

19. Shalitin S, Yackobovitch-Gavan M, Phillip M. Prevalence of thyroid dysfunction in obese children and adolescents before and after weight reduction and its relation to other metabolic parameters. Horm Res 2009;71:155-61.

20. Stichel H, l'Allemand D, Grüters A. Thyroid function and obesity in children and adolescents. Horm Res 2000;54:149.

21. Winter WE, Signorino MR. Review: molecular thyroidology. Ann Clin Lab Sci 2001;31:221-44.

22. Reinehr T, Isa A, de Sousa G, Dieffenbach R, Andler W. Thyroid hormones and their relation to weight status. Horm Res 2008;70:51-7.

23. Alevizaki M, Huhtaniemi I. Structure-function relationships of glycoprotein hormones; lessons from mutations and polymorphisms of the thyrotrophin and gonadotrophin subunit genes. Hormones (Athens) 2002;1:224-32.

24. Pfleger KD, Kroeger KM, Eidne KA. Receptors for hypothalamic releasing hormones TRH and GnRH: oligomerization and interactions with intracellular proteins. Semin Cell Dev Biol 2004;15:269-80.

25. Vassart G, Pardo L, Costagliola S. A molecular dissection of the glycoprotein hormone receptors. Trends Biochem Sci 2004;29:119-26. 